\title{
Probability Distribution of Turbulent Velocity Fluctuations in a Patchy Vegetated Open Channel
}

\section{Olatunji Peter Folorunso*}

School of Civil Engineering, University of Birmingham, Edgbaston, UK

\begin{abstract}
The probability density function (PDF) for the stream wise velocity fluctuations was obtained for various cross sections in a patchy vegetated open channel. The pdf obtained for all the cross sections appeared to be qualitatively Gaussian, hence adequate to predict the extreme values arising from coherent structures of the patchy vegetated open channel for two experimental conditions. Relative to gravel bed, it is shown that the vegetation stem density produces asymmetric velocity fluctuations over the vegetated bed due to more distortion of large scale flow structures. At the boundary region however, the $p d f$ is negatively skewed in experiment two relative to experiment one. This asymmetry is attributed to the enhanced lateral transport of momentum at the boundary region.
\end{abstract}

Keywords: Momentum; Gaussian; Open channel; Coherent structures; Probability Density Function (PDF)

\section{Introduction}

The random and unpredictable nature of turbulence requires the description of its motion through statistical measures because the instantaneous motions of turbulence are complicated to understand due to unexpected changes. A statistical description of turbulence involves a probability distribution for stationary flows over multiple realizations to determine the nature of turbulent velocity fluctuations.

A turbulent variable $u$ at a given point and time can be described by the probability density function $(\mathrm{PDF}) P(u)$ :

$$
\int_{-\infty}^{+\infty} P(u) d u=1
$$

This is particularly important because, in the statistical theory of turbulence, the probability density function provides a complete probabilistic description that permits the estimation and quantification of turbulent flow variables, for example, the tails of the $p d f$ for flow variables have been reported to be influenced by the scale of eddy motions [1]. However, to characterize more complex turbulent quantities, such as fluctating velocities, higher order moments are required [2].

The skewness provides information about the asymmetry of the PDF given as:

$$
\text { Skewness }\left(\mu_{3}\right)=\frac{u^{\prime^{3}}}{\left(u^{\prime^{\prime}}\right)^{3 / 2}}
$$

where $u^{\prime}=(u-U)$ is the turbulent fluctuating component.

For a value of zero skewness, the PDF is symmetric about the mean $u$, whilst positive and negative skewness gives an indication of a longer tail towards right or left respectively presumably due to momentum transfer in turbulence measurement [3]. The kurtosis characterizes the flatness of a $p d f$ and is given by the expression:

$$
\operatorname{kurtosis}\left(\mu_{4}\right)=\frac{u r^{4}}{\left(u r^{2}\right)^{2}}
$$

A time series with measurements clustered around the mean has low kurtosis and a time series by intermittent extreme events are characterized with high kurtosis [4].

\section{Materials and Methods}

The experiments were conducted in $22 \mathrm{~mm}$ long rectangular recirculating flume of width $\mathrm{B}=614 \mathrm{~mm}$ at the University of Birmingham. The channel is supplied from a constant head tank with a capacity of
$45,500 \mathrm{l}$ in the laboratory roof. Two flow discharges $(Q)$ were investigated $30.0 \mathrm{l} / \mathrm{s}$ and $30.50 \mathrm{l} / \mathrm{s}$ with corresponding flow depth $(H)$ of $130 \mathrm{~mm}$ and $128 \mathrm{~mm}$ and width to depth ratios $(B / H)$ of 4.7 and 4.8 respectively to achieve subcritical flow condition. In what follows these experimental conditions are referred to as EXPT1 and EXPT2 respectively. Detailed velocity measurements were made at three cross sections (CRS1, CRS2 and CRS3) at distances of $17.5 \mathrm{~m}, 17.85 \mathrm{~m}$ and $18.2 \mathrm{~m}$ respectively downstream from the channel inlet. In the results that follow, the gravel region of the bed extends over $\left(0 \leq \frac{y}{B} \leq 0.5\right)$, the interface occurs at $(\mathrm{y} / \mathrm{B} \leq 0.5)$ , and the vegetated region extends over $\left(0.5 \leq \frac{y}{B} \leq 1.0\right)$, where $y$ is thse lateral distance from the left hand side looking downstream and $B$ is the channel width. The stream wise direction $\mathrm{x}$ is in the direction of flow. The transverse direction $\mathrm{y}$ is perpendicular to $\mathrm{x}$ in the lateral direction, while the vertical direction is denoted by $\mathrm{z}$ and is perpendicular to the xy-plane (positive upwards). The corresponding time average velocity components are $\mathrm{U}, \mathrm{V}$ Y respectively with the associated fluctuating velocity components defined as u', v', y' respectively.

\section{Vegetation types and roughness generation}

Two different types of idealized vegetation are examined in conjunction [5] with the gravel roughness $\left(D_{70}=10 \mathrm{~mm}\right)$, i.e., idealized grass formed using artificial grass (Astroturf) and rigid vegetation arranged in a staggered grid formed from plastic (Figure 1). The vegetation and gravel form patches of width $0.307 \mathrm{~m}$ and length 1.825 $\mathrm{m}$ and alternate in a checkerboard formation down the channel $[6,7]$.

\section{Velocity measurement}

Velocity measurements were undertaken at all three cross sections (CRS1, CRS2, and CRS3), using a Nortek acoustic Doppler velocimeter (ADV) [8-10]. The ADV measures simultaneously the three velocity components at a frequency of $200 \mathrm{~Hz}$. A convergence test was performed to obtain an optimum sampling period at each measurement point (i.e.,

*Corresponding author: Olatunji Peter Folorunso, School of Civil Engineering, University of Birmingham, Edgbaston, UK, Tel: +44 (0)121 414 3344; E-mail: ftobex@ymail.com

Received July 07, 2017; Accepted September 28, 2017; Published October 04 2017

Citation: Folorunso OP (2017) Probability Distribution of Turbulent Velocity Fluctuations in a Patchy Vegetated Open Channel. J Civil Environ Eng 7: 284. doi: 10.4172/2165-784X.1000284

Copyright: ( $) 2017$ Folorunso OP. This is an open-access article distributed under the terms of the Creative Commons Attribution License, which permits unrestricted use, distribution, and reproduction in any medium, provided the original author and source are credited. 
60 seconds). For each cross section a vertical profile of velocity data was collected from the middle of the channel towards the channel sidewalls at $10 \mathrm{~mm}$ horizontal and vertical spacing resulting in approximately 495 measured points for a cross section.

\section{Results and Discussion}

As in Equation 1, a probability density function $P(u)$ of a random variable $u$ follows a Gaussian distribution:

$$
\mathrm{P}(\mathrm{u})=\frac{1}{\sqrt{2 \pi \sigma_{u}^{2}}} e^{-(u-U)^{2}}-\infty<x<\infty
$$

where $\sigma \mathrm{u}$ is standard deviation of the random variable with $U$ denoting the mean stream wise velocity. Probability density functions which differ from a Gaussian distribution may suggest certain features within the flow, e.g., extreme values arising from coherent structures.

The $p d f$ from the streamwise velocity fluctuation $u$ ' for different locations are shown in Figures 2 and 3. The pdf values have been normalized by Equation (5) in order to compare and contrast the fluctuating velocity distribution with Gaussian distribution for all the locations.

$$
P(u)=P\left(\frac{u-U}{\sigma_{u}}\right)
$$

The shape of the fluctuating velocities were obtained by evaluating the kurtosis and skewness of the representative points [11]. As shown in

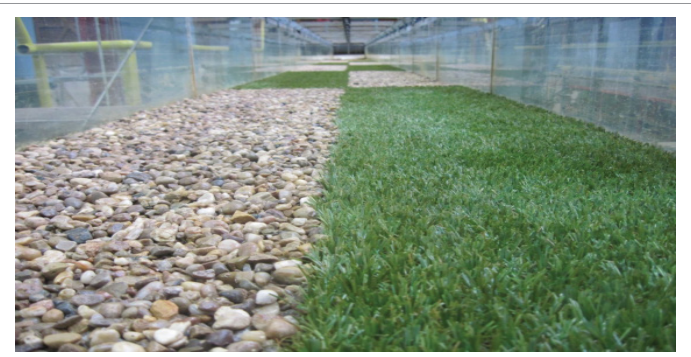

Figure 1a: Two model vegetation simulated with gravel roughness: EXPT1.

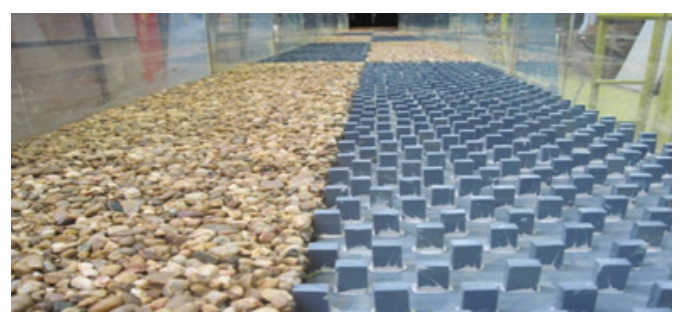

Figure 1b: Two model vegetation simulated with gravel roughness: EXPT2.

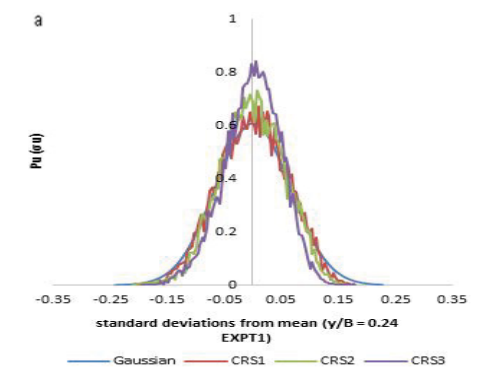

Figure 2a: Probability density function of streamwise velocity fluctuations near bed for gravel, boundary and vegetated regions $(z / H=0.07)(E X P T 1)$.

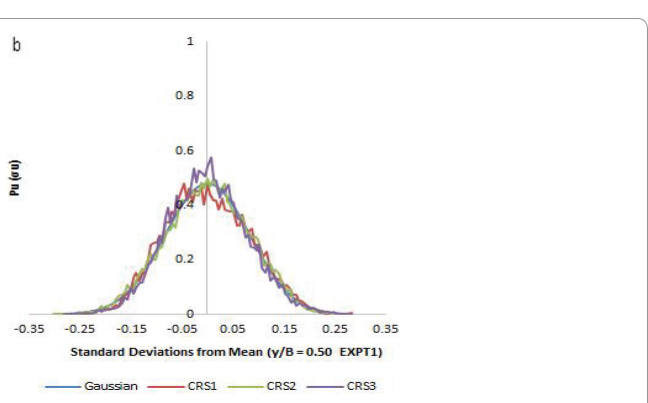

Figure 2b: Probability density function of streamwise velocity fluctuations near bed for gravel, boundary and vegetated regions $(\mathrm{z} / \mathrm{H}=0.07)(\mathrm{EXPT1})$.

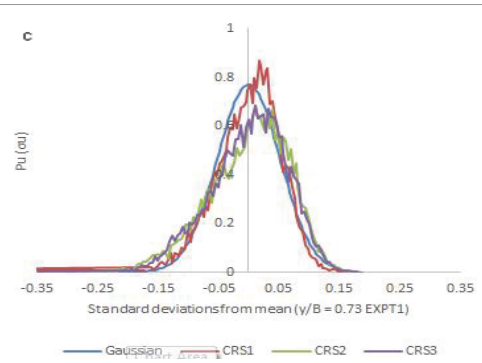

Figure 2c: Probability density function of streamwise velocity fluctuations near bed for gravel, boundary and vegetated regions $(\mathrm{z} / \mathrm{H}=0.07)$ (EXPT1).

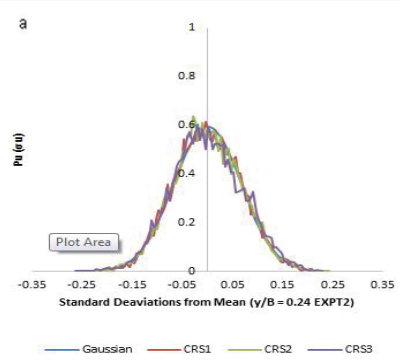

Figure 3a: Probability density function of streamwise velocity fluctuations near bed for gravel, boundary and vegetated regions $(z / H=0.07)(E X P T 2)$.

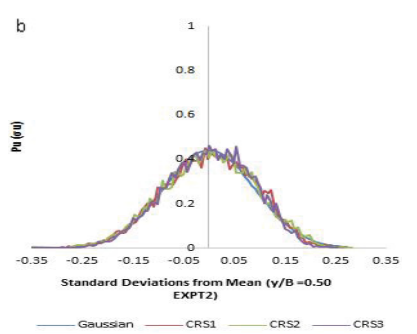

Figure 3b: Probability density function of streamwise velocity fluctuations near bed for gravel, boundary and vegetated regions $(z / H=0.07)(E X P T 2)$.

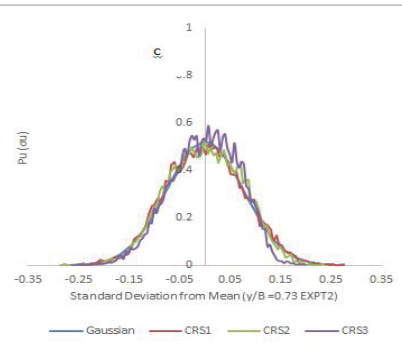

Figure 3c: Probability density function of streamwise velocity fluctuations near bed for gravel, boundary and vegetated regions $(\mathrm{z} / \mathrm{H}=0.07)(\mathrm{EXPT2})$. 
Equation (2 and 3), skewness quantifies the symmetry of a distribution with respect to its deviation from the mean. A symmetrical distribution has a skewness equal to zero. Kurtosis describes whether the shape of data distribution is peaked or flat relative to a normal distribution,

\begin{tabular}{|c|c|c|c|c|c|c|}
\hline \multicolumn{4}{|c|}{ EXPT1 } & \multicolumn{3}{|c|}{ EXPT2 } \\
\hline Variables & CRS1 & CRS2 & CRS3 & CRS1 & CRS2 & CRS3 \\
\hline \multicolumn{4}{|c|}{$\mathrm{y} / \mathrm{B}=0.24, \mathrm{z} / \mathrm{H}=0.07$} & \multicolumn{3}{|c|}{$y / B=0.24, z / H=0.07$} \\
\hline Kurtosis & 0.146 & 0.268 & 0.334 & 0.096 & 0.092 & 0.094 \\
\hline Skewr & -0.07 & -0.069 & -0.0 & 0.051 & 0.051 & 0.054 \\
\hline \multicolumn{4}{|c|}{$y / B=0.50, z / H=0.07$} & \multicolumn{3}{|c|}{$\mathrm{y} / \mathrm{B}=0.50, \mathrm{z} / \mathrm{H}=0.07$} \\
\hline Kurtosis & 0.121 & 0.123 & -0.047 & 0.072 & 0.081 & 0.078 \\
\hline Skewness & 0.0518 & -0.025 & 0.05 & -0.23 & -0.213 & -0.281 \\
\hline \multicolumn{4}{|c|}{$y / B=0.73, z / H=0.07$} & \multicolumn{3}{|c|}{$y / B=0.73, z / H=0.07$} \\
\hline Kurtosis & 0.3036 & -0.148 & 0.122 & 0.121 & 0.119 & 0.12 \\
\hline Skewness & -0.69 & -0.527 & -0.596 & 0.073 & 0.07 & 0.071 \\
\hline
\end{tabular}

Table 1: Kurtosis and Skewness values for EXPT1 and EXPT2.

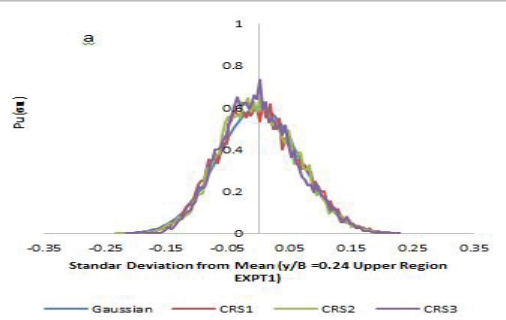

Figure 4a: Probability density function of streamwise velocity fluctuations at upper region $(\mathrm{z} / \mathrm{H}=0.61)(\mathrm{EXPT} 1)$.

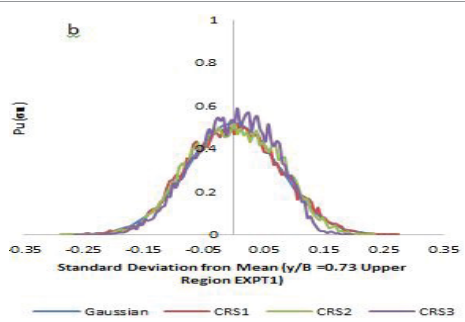

Figure 4b: Probability density function of streamwise velocity fluctuations at upper region $(\mathrm{z} / \mathrm{H}=0.61)(\mathrm{EXPT1})$.

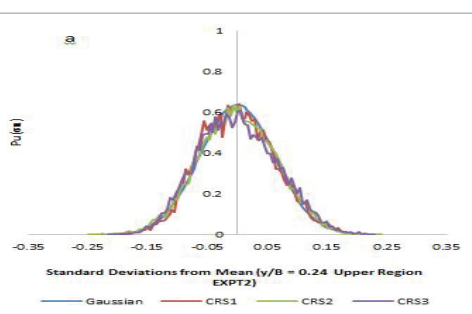

Figure 5a: Probability density function of streamwise velocity fluctuations at upper region $(\mathrm{z} / \mathrm{H}=0.61)(\mathrm{EXPT2})$.

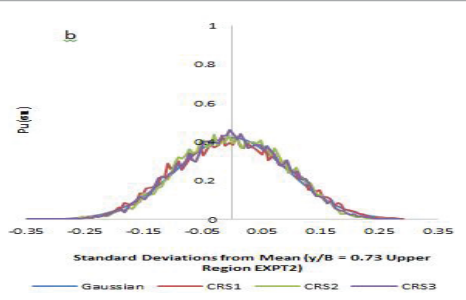

Figure 5b: Probability density function of streamwise velocity fluctuations at upper region $(\mathrm{z} / \mathrm{H}=0.61)(\mathrm{EXPT2})$. a higher kurtosis tends to exhibit a distinct peak near the mean [1214]. For quantitative comparison with the Gaussian distribution, the skewness and kurtosis factors for all the locations and cross-sections are presented in Table 1.

Figures 2 and 3 illustrates the $p d f$ of the streamwise turbulent velocity at different locations for EXPT1 and EXPT2 respectively. In the figures, the vertical axis represents the probability density functions multiplied by the corresponding standard deviation $\mathrm{P}(u)\left(\sigma_{u}\right)$ and the horizontal axis represents the number of standard deviations from the mean. As can be seen, the distribution of the streamwise turbulent velocity appears to be qualitatively Gaussian in all the cross-sections. However, for EXPT1, the $p d f$ in CRS3 over the gravel bed $(y / B=0.24)$ exhibits higher kurtosis (peakedness relative to normal distribution) but nearly Gaussiandistributed $(S=-0.0456, K=0.3343$ ) Figure 2a, where $S$ and $K$ are the skewness and kurtosis respectively. This kurtosis distribution of the fluctuating velocity is similar to that obtained for CRS1 over the flexible vegetated bed $(y / B=0.73)$ as illustrated in Figure $2 \mathrm{c}$. This can attributed to the location of maximum streamwise velocities being displaced between regions of different cross-sections due to heterogeneous roughness $[15,16]$. However, over the flexible vegetated bed $(y / B=0.73)$ in EXPT1 (Figure 2c), the velocity fluctuations slightly deviates from Gaussian, given negative skewness $(S=-0.6903,-0.5266,-0.5955)$ for CRS1, CRS2 and CRS3 respectively. This is attributed to the possible effect of flexible vegetation roughness on the flow: as the flow accelerates over the preceding gravel bed to the new flexible vegetated bed in EXPT1, the velocity of the flow decreases due to vegetation stem density [17-20]. It can therefore be suggested that, the flow deceleration due to vegetation stem density produces an asymmetric velocity fluctuation over the vegetated bed due to more distortion of large scale structures [21], thereby becoming more asymmetric and in turn manifested in the actual fluctuations [22]. It should be noted however in Figure 2b that the probability density functions for the fluctuating velocities show qualitative similarities in shapes with Guassian distribution for all the cross-sections at the roughness boundary region $(y / B=0.50)$ in EXPT1, confirming the uniform flow for the experiment [23-26]. The distribution is seen to be symmetric about the mean value and the width of the distribution increases on both sides relative to gravel $(y / B$ $=0.24)$ and vegetated $(y / B=0.73)$ regions respectively, hence the $p d f$ show flat peak $(K=0.1216,0.1237,-0.0476)$ corresponding to Figure $2 b$ at the boundary region. Such flat peaks and increased $p d f$ widths are not formed over the gravel and vegetated regions in EXPT1.

In EXPT2 (Figure 3), the pdf exhibits extended long tails at both sides relative to EXPT1. As can be see from the figure, the $p d f$ of streamwise velocity fluctuations demonstrate near Gaussian behaviour at every region and for all the cross-sections with lower kurtosis relative to EXPT1. At the boundary region $(y / B=0.5)$ however, the $p d f$ is negatively skewed in EXPT2 (Figure $3 b$ ) relative to EXPT1 (Figure $2 b$ ). This asymetry may be attributed to the enhanced lateral transport of momentum [27] at the boundary region in EXPT2. The skewness of the streamwise turbulent velocity over the vegetated bed in EXPT1 (Figure 2c) and at the roughness boundary region in EXPT2 (Figure $3 \mathrm{~b}$ ) highlights the differences in flow behaviour which occurred at the different regions of the channel bed [28]. The major asymmetry of the distribution appears to be located in these regions of the channel. This may not be unexpected since these regions are the high shear regions which leads to frequent momentum transfer $[29,30]$. It appears from Figure 3 that the fluctuating streamwise velocities may have a more Gaussian $p d f$ in EXPT2 relative to EXPT1, the distribution however exhibits long tail (negative skewed) at the roughness boundary region $(y / B=0.50)$. 
From Table 1 the values of skewness over the flexible vegetated region $(y / B=0.73)$ in EXPT1 and roughness boundary region $(y / B=$ $0.50)$ in EXPT2 are much greater with negative values than those at the gravel $(y / B=0.24)$ region; these regions of high negative skews are assumed to be the shear regions $[31,32]$. These values confirmed the $p d f$ distributions shown in Figures 2 and 3. The negative skewness can be attributed to the large scale vertical and horizontal motions induced by significant shear layer over the vegetated bed in EXPT1 and the roughness boundary region in EXPT2 respectively. The kurtosis values are higher in EXPT1 relative to EXPT2, with higher values indicating a sharp peaked distribution suggesting intermittent extreme event over the vegetated region in EXPT1. This behavior in EXPT2 with lower kurtosis values indicates flat distributions of stream wise turbulent velocity. More symmetrical distributions of turbulent velocities occur for increased distance above the bed $(z / H=0.61)$ due to less significant effects of the bed roughness at the upper region of the flow as illustrated in Figures 4 and 5. It should be noted that the differences outlined between the normal distribution and the data collected leads to assume that the flow is normal $[33,34]$.

\section{Conclusion}

Based on the measurements, the main findings of the research are highlighted as follows:

- In addition to the general discussion above, it can be seen from Figures 2 and 3 that, the scale and shape of the $p d f$ distribution of the streamwise turbulent velocities varies laterally within the channel. This highlights the variation in casual mechanism pertaining to velocity fluctuations.

- In EXPT1, the flow deceleration of the streamwise velocity component due to flexible vegetation density produces an asymmetric velocity fluctuation over the vegetated bed (Figure 2c), this is attributted to a more distortion of large scale structures due to stem density and oscillations which becomes more asymmetric and in turn manifested in the actual velocity fluctuations.

- The large (negative) values of skewness over the flexible vegetated region $(y / B=0.73)$ in EXPT1 and roughness boundary region $(y / B=$ 0.50 ) in EXPT2 (Table 1) suggests that the velocity fluctuation in these regions do not follow Gaussian distribution and has long negative tails, these regions of high negative skews are assumed to be the shear regions for the flow.

\section{References}

1. Afzalimehr H, Dey S (2009) Influence of bank vegetation and gravel bed on velocity and Reynolds stress distributions. Int J Sediment Res 24: 236-246.

2. Cea L, Puertas J, Pena L (2007) Velocity measurements on highly turbulent free surface flow using ADV. Exp Fluids 42: 333-348.

3. Cheng NS, Nguyen HT, Tan SK, Shao S (2012) Scaling of velocity profiles for depth-limited open channel flows over simulated rigid vegetation. J Hydraul Eng 138: 673-683.

4. Chow VT (1959) Open-channel hydraulics. McGraw-Hill, Singapore.

5. Chu CR, Parlange MB, Katul GG, Albertson JD (1996) Probability density functions of turbulent velocity and temperature surface layer. Water Resources Research 32: 1681-1688.

6. Daniel E, John PC (2007) The accuracy of acoustic Doppler velocimetry measurements in turbulent boundary layer flows over a smooth bed. Limnol Oceanogr Methods 5: 23-33.

7. Finnigan J (2000) Turbulence in plant canopies. J Fluid Mech ss32: 519-571.

8. Ghisalberti M, Nepf $\mathrm{H}(2006)$ The structure of the shear layer over rigid and flexible canopies. Environ Fluid Mech 6: 527-551.
9. Ghisalberti M, Nepf HM (2004) The limited growth of vegetated shear layers. Water Resource Res 40: 1-12.

10. Goring DG, Nikora VI (2002) Despiking acoustic Doppler velocimeter data. J Hydraul Eng 128: 117-126.

11. Hofland B, Battjes J (2006) Probability density of instantaneous drag forces and shear stresses on a bed. J Hydraul Eng 132: 1169-1175.

12. Hwang L, Laursen EM (1963) Shear measurements technique for rough surfaces. J Hydraul Eng 89: 19-37.

13. Ikeda S, Ohta K (1995) Flow over flexible vegetation and 3-D structure of organized vortex associated with honami. Journal of Hydraulic, Coastal and Environmental Enginerring 515: 33-43.

14. Ikeda S, Ohta K, Hasegassswa $H$ (1994) Instability-induced horizontal vortices in shallow open channel flows with an inflexion possessing in skewed velocity profile. Journal of Hydroscience and Hydraulic Engineering 12: 69-84.

15. Jesson M, Sterling M, Bridgeman J (2010) Turbulent structures in heterogenous channels and their effects on conyeyance. First IAHR European Div. Congress., International Association for Hydro-Environment Engineering and Research (IAHR) Spain.

16. Jesson M, Sterling M, Brigdeman J (2013) Modelling flow in an open channe with heterogeneous bed roughness. J Hydraul Eng 139: 195-204.

17. Jesson M, Sterling M, Bridgeman J (2012) An experimental study of turbulence in a heterogeneous channel. Water Management Proceedings of the Institution of Civil Engineers 166: 16-26.

18. Kouwen N, Unny TE (1980) Flexible roughness in open channels. J Hydraul Eng -Asce, 99: 713-727.

19. Lacey RWJ, Roy AG (2008) Fine-scale characterization of the turbulent shear layer of an instream pebble cluster. J Hydraul Eng 137: 925-926.

20. Lane SN, Biron PM, Bradbrook KF, Butler JB, Chandler JH, et al. (1998) ThreeDimensional measurement of river channel flow processes using acoustic Doppler velocimetry. Earth Surface Processes and Landforms 23: 1247-1267.

21. Liu D, Diplas P, Fairbanks JD, Hodges CC (2008) An experimental study of flow through rigid vegetation. J Geophys Res 113: 1-16.

22. Lohrmann A, Cabrera R, Kraus NC (1994) Acoustic Doppler velocimeter (ADV) for laboratory use. Fundamentals and advancements in hydraulic measurements and experimentation. Buffalo, New York, USA. ASCE 351-365.

23. Mclelland SJ, Nicholas AP (2000) A new method for evaluating errors in high frequency ADV measurements. . Hydrological processes 14: 351-366.

24. Nepf HM (2012) Hydrodynamics of vegetated channels. J Hydraul Res 50: 262279

25. Nepf H, Ghisalberti M (2008) Flow and transport in channels with submerged vegetation. Acta Geophysical 56: 753-777.

26. Nepf HM,Vivoni ER (2000) Flow structure in depth-limited, vegetated flow. Journal of Geophysical Research 105: 28547-28557.

27. Nezu I, Nakagawa H (1993) Turbulence in open-channel flows. Journal of Hydraulic Engineering 120:1235-1237.

28. Rahman S, Webster DR (2005) The effect of bed roughness on scalar fluctuations in turbulent boundary layers Exp Fluids 38: 372-384.

29. Shiono K, Muto $Y$ (1998) Complex flow mechanisms in compound meandering channels with overbank flow. J Fluid Mech 376: 221-261.

30. Shiono K, Knight DW (1991) Turbulent open-channel flows with variable depth across the channel. J. Fluid Mech 222: 617-646.

31. Vermaas DA, Uijttewaal WS, Hoitink A (2010) Lateral transfer of streamwise momentum caused by a roughness transition across a shallow channel. Water Resources Res 47: 1-12.

32. Vermaas DA, Uijttewaal WS, Hoitink AJ (2007) Effect of Heterogeneous Bed Roughness on the Conveyance Capacity of Floodplains. Netherlands Centre for River Studies pp. 34-35

33. Voulgaris G, Trowbridge JH (1998) Evaluation of the acoustic Doppler Velocimeter (ADV) for turbulence measurements. J Atmospheric Ocean Technol 15:272-289.

34. Wilson CAME, Horritt MS (2002) Measuring the flow resistance of submerged grass. Hydrol Process 16: 2589-2598. 